\title{
Impaired microvascular hyperaemic response to minor skin trauma in type I diabetes
}

\author{
G RAYMAN, S A WILliAMS, P D SPENCER, L H SMAJE, P H WISE, J E TOOKE
}

\begin{abstract}
The microvascular response of foot skin to minor thermal injury and the skin of the anterior abdominal wall to injury from a needle was assessed by laser Doppler flowmetry in 23 patients with type I diabetes and 21 healthy control subjects. After minor thermal injury mean (SD) maximum skin blood flow was significantly lower in the diabetic group than the control group $(0.53$ $(0.11) v 0.72(0.10) \mathrm{V}$, in arbitrary units of flow, respectively, $\mathbf{p}<\mathbf{0 . 0 0 1}$ ) and was negatively correlated with the duration of diabetes $(r=-0.60 ; p<0 \cdot 01)$. After needle injury a similar pattern of impairment was seen, the peak flow value recorded being significantly lower in the diabetic group than the control group $(0.28(0.10) v 0.41(0.09) \mathrm{V}$, respectively; $\mathrm{p}<0.001)$ and also negatively correlated with the duration of diabetes $(r=-0.61$; $\mathbf{p}<0.01)$. There was a significant relation between the response obtained at the two sites of injury in the diabetic group $(r=+0.72$, $\mathbf{p}<0.001$ ) but not in the control group. The impairment in response was not related to diabetic control and was not explicable in terms of a reduction in superficial skin capillary density.

The inability of the diabetic skin microvasculature to respond normally to injury may be an important factor in the development of foot ulceration that often follows minor trauma.
\end{abstract}

\section{Introduction}

The disabling foot complications of diabetes are often precipitated by minor mechanical or thermal injury, suggesting disturbance of the healing process. An important component of the normal reaction to injury is hyperaemia, and, although measurement of blood flow after hyperaemic stimuli, such as release of arterial

\footnotetext{
Departments of Physiology and Endocrinology, Charing Cross and Westminster Medical School, London

G RAYMAN, MB, MRCP, senior medical registrar

S A WILLIAMS, BSC, MB, research fellow

P D SPENCER, MB, PHD, lecturer

L H SMAJE, MB, PHD, professor of physiology

P H WISE, PHD, FRCP, consultant physician, department of endocrinology

J E TOOKE, DM, MRCP, Wellcome senior lecturer in medicine and physiology

Correspondence to: Dr G Rayman, Ipswich Hospital, Ipswich, Suffolk IP4 5PD.
}

occlusion and exercise, suggests a limitation of maximum perfusion in diabetics, ${ }^{1.2}$ no study has specifically examined the skin microvascular hyperaemic response to injury. The development of the laser Doppler flowmeter allows repeated non-invasive study of superficial microvascular flow in small areas of the skin and thus may be used to investigate the hyperaemic response to minor injury.

In this study laser Doppler flowmetry was applied to determine whether diabetics without large vessel disease showed evidence of limited microvascular perfusion in response to two distinct noxious stimuli in different areas of the skin. In addition, as the flowmeter measures volumetric flow (quantity and velocity of moving red blood cells) ${ }^{+6}$ the number of superficial skin capillary loops $/ \mathrm{mm}^{2}$ was estimated by television microscopy to find out whether any observed differences in flow were related to the density of the capillaries.

\section{Patients and methods}

A total of 23 patients ( 13 men, 10 women) with type I diabetes and 21 healthy control subjects ( 11 men, 10 women) were studied. The diabetic patients were volunteers randomly selected from the Charing Cross diabetic clinic. Controls comprised academic and technical staff from the medical school. Mean (SD) duration of diabetes was 13.3 (8.8) years (range 1-29 years), and mean age of the diabetic group was $30.9(6.4)$ years (18-45) compared with $29 \cdot 7(5 \cdot 2)$ years $(20-40)$ for the control group. Smokers and hypertensive subjects were excluded from the study, and none of the subjects had a history of complications of the foot. All subjects had normal ankle reflexes. Vibration sensory thresholds at the big toes, measured with a biothesiometer (Biomedical Instrument Company, Ohio), were within the normal centiles for age assessed with centile charts. ${ }^{6}$ Severe large vessel disease was excluded by normal ankle to arm systolic blood pressure ratios.? Seven patients had independent ophthalmological evidence of minimal background retinopathy, but no patient had persistent proteinuria. Patients with a history of ketosis in the past six months were not selected for study.

Diabetic control was assessed by measuring blood glucose concentration at the time of the study and glycosylated haemoglobin concentration. To examine the short term effect of change in diabetic control in a given subject 10 diabetics who had glucose concentrations $<10 \mathrm{mmol} / 1(<180 \mathrm{mg} / 100 \mathrm{ml})$ when first studied were restudied after omitting to take their insulin before breakfast (mean (SD) blood glucose at the time of study $17 \cdot 6(3 \cdot 6) \mathrm{mmol} / \mathrm{l}$ (317 (65) $\mathrm{mg} / 100 \mathrm{ml})$ ).

All studies were conducted after a minimum acclimatisation period of 30 minutes in a temperature controlled environment (mean (SD) $22(1)^{\circ} \mathrm{C}$ ) in quiet surroundings. Subjects were rested on a specially constructed couch that allowed passive lowering of either leg. 


\section{MEASUREMENT OF BLOOD FLOW}

Blood flow was measured with a laser Doppler flowmeter (Periflux model PFIC, Mk II, Perimed Limited, Sweden). Red laser light produced by the instrument is conducted to the skin surface by a single fibre optic light guide, held in place on the skin by a plastic probe holder. The backscattered light, some of which is altered in frequency by red cells moving in the microvasculature, is returned to the instrument by fibre optic light guides contained within the same probe as the incident light guide. Dual efferent light guides are used to reduce "noise" resulting from variations in the light signal. The frequency shift of the backscattered light is detected by the instrument, which produces a voltage signal directly proportional to the quantity of blood flow (velocity and number of red cells) in the microvasculature of superficial skin. ${ }^{+5}$ In practice, the pencil like probe is placed in the probe holder affixed to the surface of the skin with double sided sticky tape, and blood flow is recorded on a chart recorder in arbitrary units of volts.

\section{INJECTION TRAUMA}

Blood flow measurements were made from the skin of the upper abdomen just below the costal margin, $8-10 \mathrm{~cm}$ lateral to the midline (about T9 dermatome). Flow was recorded from both right and left sides and results given as the mean of the two sites. After the resting flow had been recorded for five minutes the laser probe was removed from its holder and injection trauma produced by inserting a 25 gauge needle into the skin in the exact centre of the probe holder to a depth of $0.5 \mathrm{~cm}$, previously set by a needle guard.

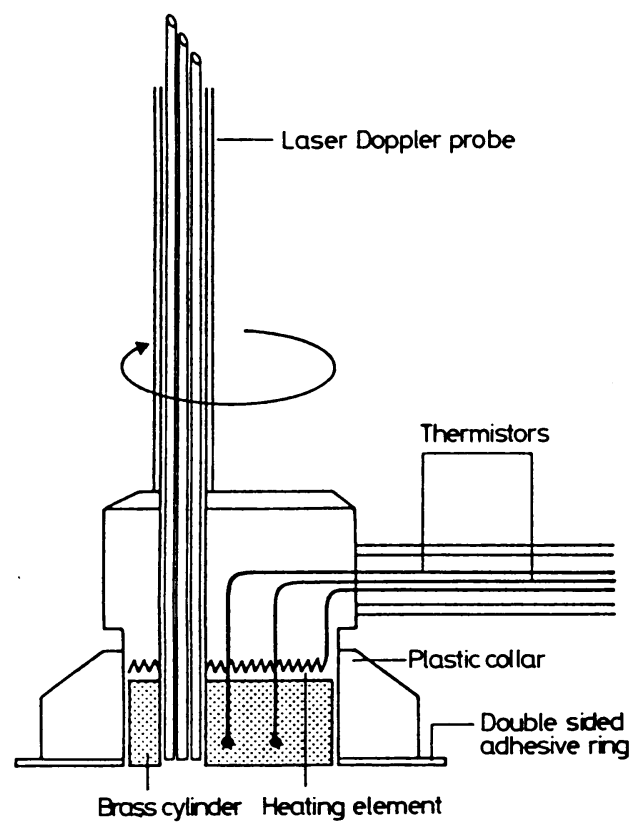

FIG 1 - Cross sectional diagram of heating probe with modified laser Doppler probe in place. Rotation of heating probe within plastic collar is indicated by arrow.

Preliminary studies showed that a predictable peak in laser Doppler flow that in normal subjects was roughly 20 times the resting flow value developed within 15 minutes of the injection. Thereafter flow values rapidly fell to five times rest flow values over the first two hours, gradually returning to normal over the next two or three days. Thus to derive peak flow after needle injection the following measurement procedure was followed: the Doppler probe was immediately replaced and flow recorded continuously for the first 15 minutes and thereafter for five minute periods at 30 and 60 minutes. Fifteen minutes after the first needle prick had been given the manoeuvre was repeated on the opposite side of the abdomen. If any bleeding occurred the results were considered to be invalid, and a new site was chosen. The technique was reproducible with a coefficient of variation of $8.6 \%$ determined from nine duplicate pairs.

\section{THERMAL INJURY}

Mild thermal injury was produced by heating the skin on the dorsum of the foot to $44^{\circ} \mathrm{C}$ for 30 minutes. The heating probe supplied by the manufacturers was inadequate as it did not contain a feedback thermostat, the heat distribution was uneven, and the central area over which blood flow was to be measured was not directly heated; thus a heated probe holder was specially constructed. This consisted of a cylindrical brass core heated by $\&$ thermostatically controlled element (fig 1). The circular end face (diameter $0.9 \mathrm{~cm}$ ) was held in direct contact with the area of the skin to be heated bf being placed in a plastic collar previously affixed to the skin by a double sided adhesive ring. The heated probe holder had a small diameter $(2.4 \mathrm{~mm})^{5}$ eccentrically placed channel through which a modified fine bore lase $\mathbb{D}$ Doppler probe tip could be inserted. Rotation of the heated probe holder about the plastic collar allowed blood flow to be measured from an area thap had been directly heated immediately before rotation. In this way the mear: flow for nine separate areas $\left(40^{\circ}\right.$ rotations) could be determined, which was more reproducible than a single measurement (coefficient of variation was $7 \cdot 6 \%$ when determined from duplicate experiments in nine subjects compared with a mean coefficient of variation of $16.3 \%$ for repeat single point measurements).

Blood flow was recorded from the heated skin after the foot had beeñ lowered passively $50 \mathrm{~cm}$ below the level of the heart. Local heating to $44^{\circ} \mathrm{C}$ removes postural regulation of blood flow, which normally results in a reduction of blood flow on dependency. By lowering the leg and thereby. increasing hydrostatic pressure and passively dilating the blood vessels, we found that skin blood flow was maximised.

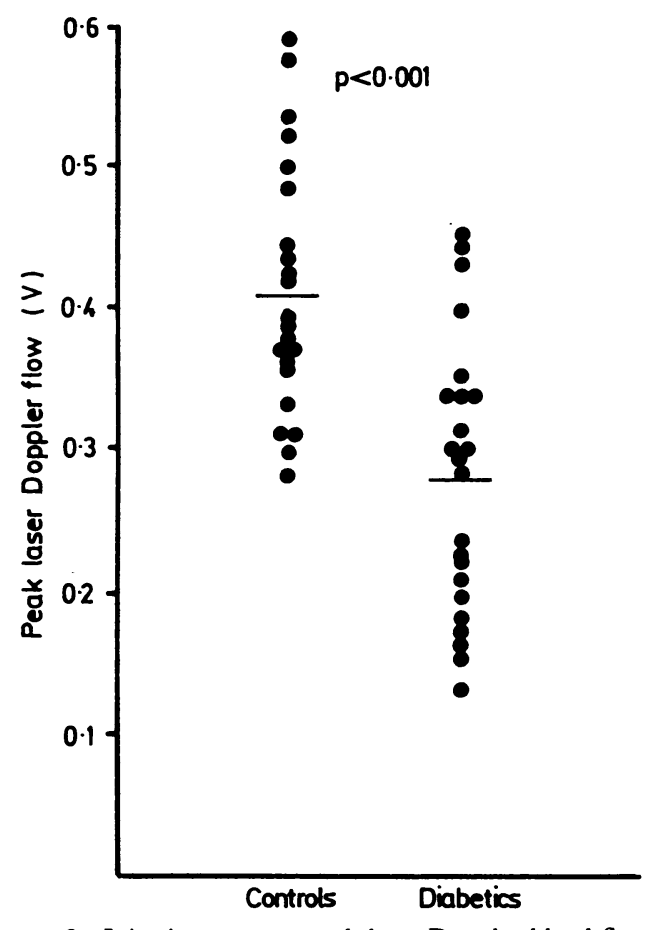

FIG 2-Injection trauma: peak laser Doppler blood flow response in diabetics and controls. Bars represent means.

\section{NUMBER OF CAPILLARIES}

The apexes of superficial dermal capillary loops were visualised with a television-microscope system as previously described. ${ }^{8}$ Using this system, we recorded on video tape images from an area of skin on the dorsum of the foot, which were then analysed by two independent observers to derive the mean number of capillaries $/ \mathrm{mm}^{2}$ of the skin surface. The number of capillaries were counted in 16 of the diabetics and 14 control subjects from the original groups.

\section{STATISTICAL METHODS}

The results are expressed as mean (SD). Differences between the groups were analysed with the Mann-Whitney U test.

\section{Results}

Injection trauma-Mean (SD) resting blood flow was not significantly different in the two groups (diabetics $0.018(0.006) \mathrm{V}$; controls $0.017(0.006) \stackrel{?}{\text { ? }}$ 
V). After needle injury in both groups blood flow showed an immediate and substantial increase, peaking 10-15 minutes later, followed by a fall towards the flow at rest, with a similar time course in the two groups. Mean peak blood flow was significantly lower in the diabetic group than the control group $(0.41(0.09) v 0.28(0 \cdot 10) \mathrm{V}$, respectively; $<<0.001)$ (fig 2). Peak blood flow did not correlate with age in either group but was inversely related to the duration of diabetes $(r=-0.61 ; p<0.01)$ (fig 3).

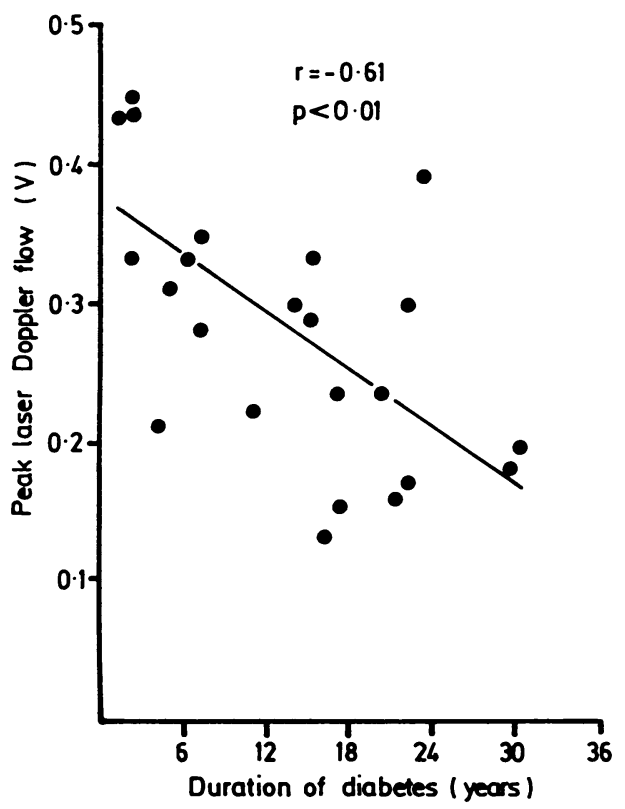

FIG 3-Relation between peak blood flow response to injection trauma and duration of diabetes. Regression line is indicated.

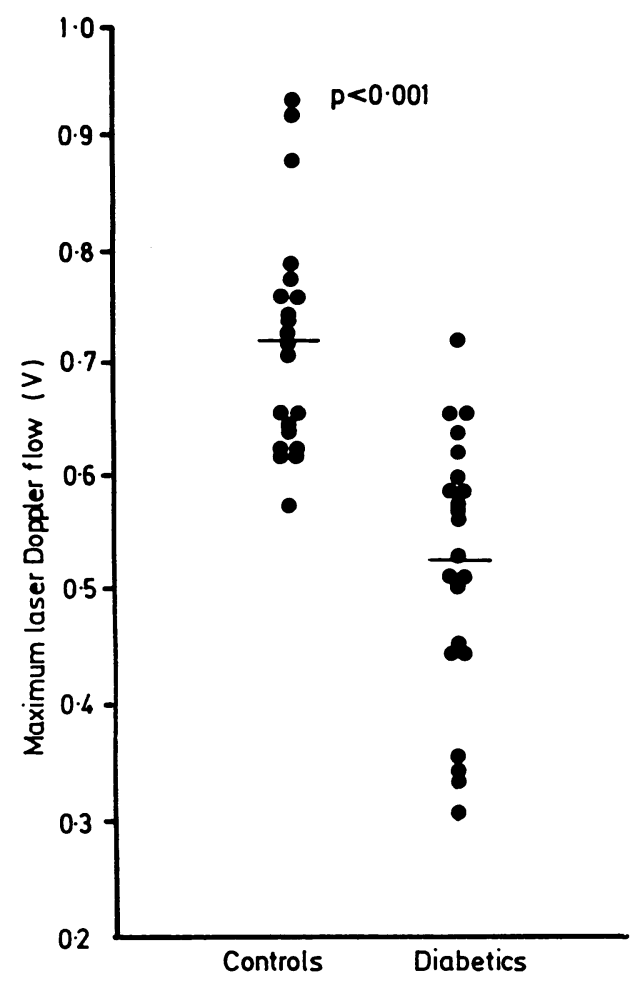

FIG 4-Mild thermal injury: maximum laser Doppler blood flow in diabetics and controls. Bars represent means.

Heat trauma-Mean maximum skin blood flow was significantly lower in the diabetic group than the control group $(0.72(0.10) v 0.53(0.11) \mathrm{V}$, respectively; $\mathrm{p}<0.001$ ) (fig 4 ). As with the response to injection trauma, maximum skin blood flow did not correlate with age in either group but was inversely related to the duration of diabetes $(r=-0.60 ; p<0.01)$ (fig 5$)$.
Maximum blood flow response to thermal injury showed a significant correlation with the peak blood flow after injection trauma in the diabetic group ( $r=0 \cdot 72 ; p<0 \cdot 001$ ) (fig 6a) but not in the control group (fig $6 b$ ).

Capillary numbers-The mean number of skin capillaries was not significantly different in the two groups (diabetics $52.7(8.7)$; controls 50.7 $(5 \cdot 7)$ ). Maximum blood flow in the foot did not correlate with the number of capillaries in either group.

Influence of diabetic control-In the diabetic group skin blood flow response to both injection trauma and thermal injury did not correlate with blood glucose concentrations at the time of the study or glycosylated haemoglobin concentrations. Withdrawal of insulin and hyperglycaemia (mean glucose concentration $17 \cdot 6(3 \cdot 6) \mathrm{mmol} / \mathrm{l}(317(65) \mathrm{mg} / 100 \mathrm{ml})$ ) had no significant effect on either the response to injection trauma $(0.23(0.07)$ controlled $v 0.24(0.07)$ uncontrolled; NS) or the response to thermal injury $(0.48(0.13)$ controlled $v 0.47(0.11)$ uncontrolled; NS $)$.

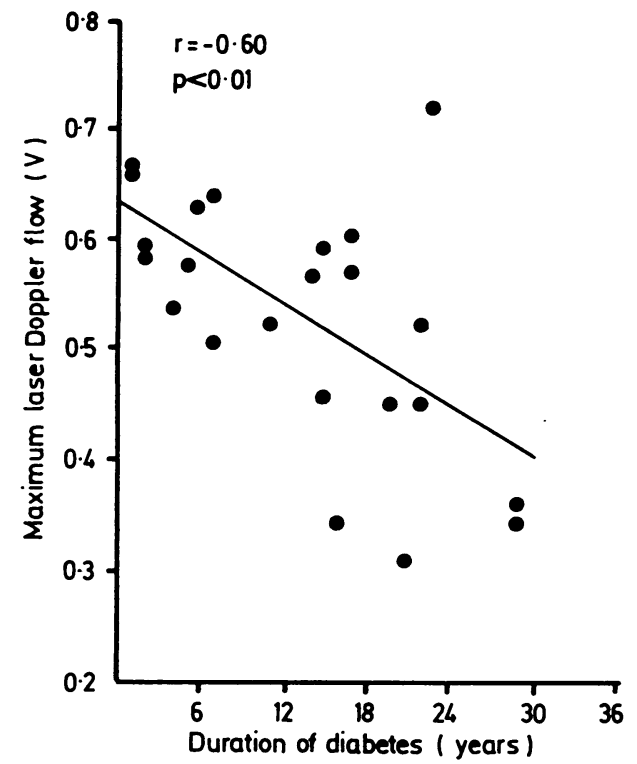

FIG 5-Relation between maximum blood flow values in response to thermal injury and duration of diabetes. Regression line is indicated.

\section{Discussion}

This is the first study to show an impaired skin microvascular vasodilator response to local trauma in patients with diabetes. Although impaired vasodilatation of the peripheral circulation in diabetes has been inferred from several previous studies, interpretation has been difficult owing to the methods used. There are theoretical problems in deriving blood flow values from xenon clearance studies, ${ }^{9}$ and in most studies of diabetics in which this technique has been used muscle rather than skin blood flow has been examined. In some studies venous occlusion plethysmography has been used, which when applied to the calf measures predominantly muscle arterial inflow ${ }^{10}$ and even when applied to the digit or foot measures total tissue perfusion rather than superficial skin blood flow. ${ }^{11} 12$ In addition, the method for provoking hyperaemia in previous studies has been indirect-for example, body heating ${ }^{10}$ relied on exercise or vascular occlusion,,${ }^{1.3}$ or used vasodilators, ${ }^{10}{ }^{12-14}$ none of which may be guaranteed to reflect the mechanisms that occur naturally in hyperaemia of injury. The only technique that uses direct thermal injury is that of transcutaneous oxygen tension measurement, but many factors other than limitation of microvascular perfusion influence this measurement. ${ }^{15}$ Thus increased skin thickness, reduced oxygen diffusion, increased oxygen affinity of haemoglobin, or increased skin metabolism may explain the low values observed in diabetics. ${ }^{16}$

Laser Doppler flowmetry is a completely non-invasive method and may be used to measure skin microvascular blood flow at the point of injury. Synchronous assessment of skin microvascular 


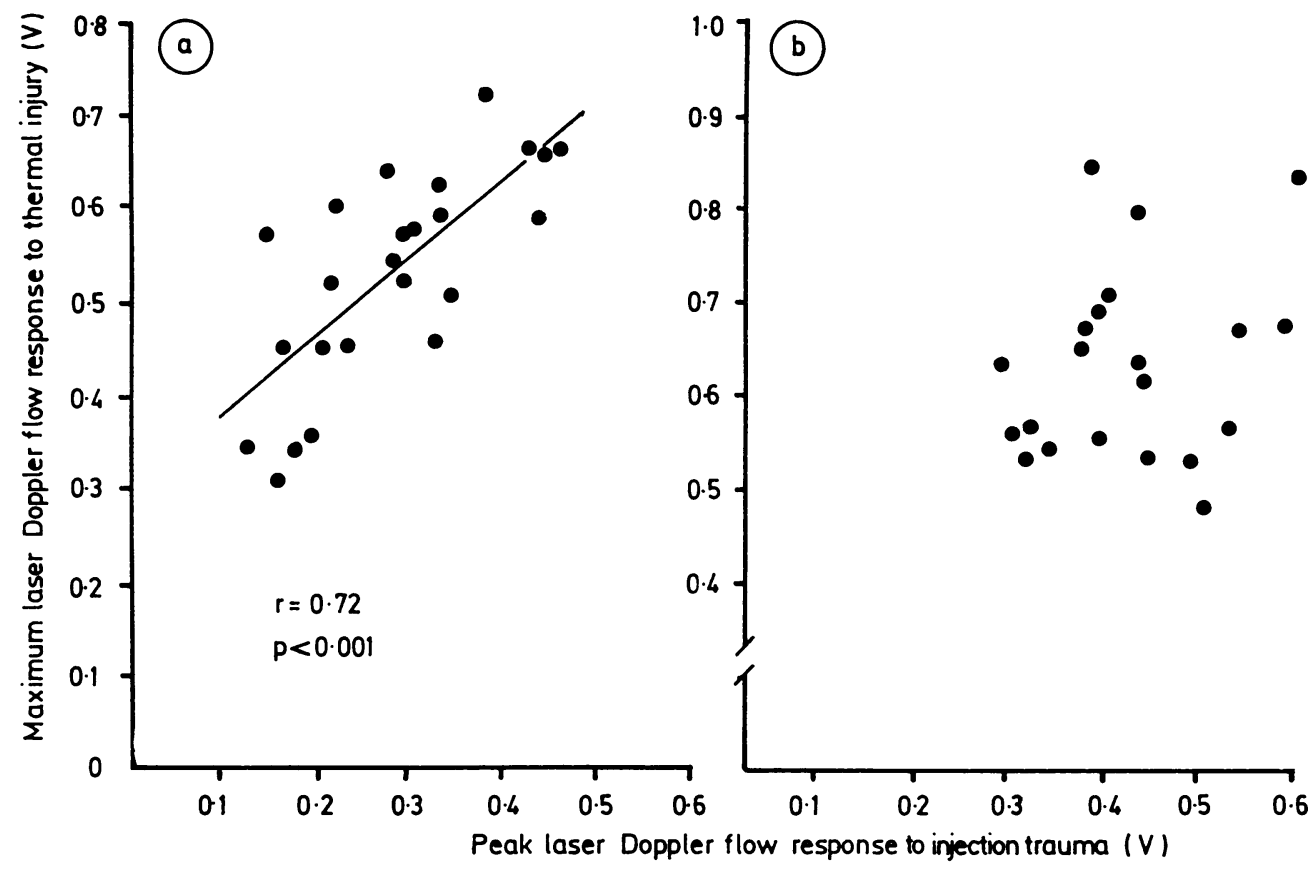

FIG 6-Relation between maximum laser Doppler blood flow response to heat trauma and peak laser Doppler blood flow response to injection trauma in the diabetic group (a) and the control group (b). Regression lines are indicated.

blood flow with laser Doppler flowmetry and direct capillary flow measurements with television microscopy suggests broad comparability between these two methods. ${ }^{17}$

The reduction in hyperaemic response to two different types of injury cannot be explained by a reduction in capillary numbers that is related to duration of diabetes, as mean density of capillaries in the two groups was similar and there was no correlation between the blood flow value and the number of capillaries on an individual basis. The finding of the correlation in impaired hyperaemic responses to injury in widely separated sites on the skin suggests that this microvascular abnormality may be a widespread feature in diabetics.

The impaired vasodilator response observed may represent a failure of release of local vasoactive mediators. This suggestion is supported by the observation that the response of the flare of histamine is reduced in diabetics ${ }^{18}$ and also by the recent finding that substance $P$, a potent neurogenic vasodilator, is depleted in diabetic nerves. ${ }^{19}$ An alternative explanation for the limited vasodilatation may be an impaired microvascular response to released vasoactive mediators, perhaps having a structural basis in the microvascular wall thickening and reduced distensibility that characterises long standing diabetes. ${ }^{20}$

The laser Doppler technique appears to be ideally suited for the study of the microvascular response to vasoactive mediators and their blockade. The clarification of the underlying mechanism may be important for improving the cutaneous microvascular response to the injury initiating many diabetic foot complications. The lack of relation of the response with retrospective and current diabetic control emphasises the complexity of the abnormality described and the need for further study.

GR was supported by the North West Thames Area Health Authority with a locally organised research grant, and JET by a Wellcome Trust senior lectureship. We thank Dr David Delpy, medical physics department, University College Hospital, for developing the thermostatically controlled heating element.

\section{References}

I Alpert JS, Coffman JD, Balodimos MC, Koncz L, Soeldner JS. Capillary permeability and blood flow in skeletal muscle of patients with diabetes mellitus and genetic prediabetes. $N \mathrm{Engl} / \mathrm{Med}$ 1972;2:454-9.

2 Christensen NJ. Muscle blood flow measured by Xenon- 133 and vascular calcification in diabetes. Acta Med Scand 1968;183:449-54.
3 Leinonen H. Matikainen E, Juntunen J. Permeability and morphology of skeletal muscle capillaries in Type I (insulin dependent) diabetes mellitus. Diabetologia 1982;22:158-62. Stern MD. In vivo evaluation of the microcirculation by coherent light scattering. Nature 1975:254:56-8.

5 Nilsson GE, Tenland T, Oberg PA. A new instrument for continuous measurement of tissue bloct flow by light beating spectroscopy. IEEC Transactions on Biomedical Engineering 1980;27:1-8 6 Bloom S, Till S, Sonksen P, Smith S. Use of a biothesiometer to measure individual vibratiof thresholds and their variation in 519 non-diabetic subjects. Br Med $\mathrm{f}$ 1984;288:1793-5.

Yao JST, Hobbs JT, Irvine WT. Ankle svstolic pressure measurements in arterial disease

affecting the lower extremities. Br J Surg 1969;56:676-80.
8 Fagrell B, Fronek A, Intaglietta M. A microscope-television system for studying flow velocity io human skin capillaries. Am $\mathcal{J}$ Physiol 1977;232:318-21.

9 Spence VA, McCollum PT, Walker WF. Comparative studies of cutaneous haemodynamics i regions of normal and reduced perfusions. Practical aspects of skin blood flow measurement: $B E \mathbb{D}$ regions of normal and reduced perfusions. Practical aspects of skin blood flow measurement: $B E$ 용

Greeson TP, Freedman RI, Levan NE, Wong WH. Cutaneous vascular responses in diabetic Microvascular Res 1975;10:8-16.

11 Christensen NJ. Spontaneous variations in resting blood flow, postischaemic peak flow an $\overline{\bar{\Phi}}$ vibratory perception in the feet of diabetics. Diabetologia 1969;5:171-8.

12 Megibow RS, Megibow SJ, Pollack H, Bookman JJ, Osserman K. The mechanisms of accelerated peripheral vascular sclerosis in diabetes mellitus. Am J Med 1953;15:316-21

13 Mendowitz M, Grossman EB, Alpert S. Decreased hallucal circulation, an early manifestation of. vascular disease in diabetes mellitus. Am f Med 1953;15:316-21

14 Barany FR. Abnormal vascular functions in diabetes mellitus. Acta Med Scand [Suppl] 1955:304

15 Spence VA, McCollum PT. Evaluation of the ischaemic limb by transcutaneous oxymetry In: Diagnostic techniques and assessment. Procedures in vascular surgery. New York: Grune and
Stratton 1985:331-41.

16 Railton R, Newman P, Hislop J, Harrower ADB. Reduced transcutaneous oxygen tension an impaired vascular response in Type I (insulin-dependent) diabetes. Diabetologia 1983;25:340-20

7 Tooke JE, Ostergren J, Fagrell B. Synchronous assessment of human skin microcirculation b laser Doppler flowmetry and dynamic capillaroscopy. Intemational fournal of Microcirculation? laser Doppler flowmetry and dynamic capillaroscopy. Intermational fournal of Microcirculation
Clinical and Experimental 1983;2:277-84.

18 Starr I. Studies on the circulation of the feet in diabetes mellitus with and without gangrene? Diabetes 1930;28:970-3

19 Clements RS, Arnin N, Leeman S. Abnormal neuronal metabolism of substance $P$ in diabeti尺 neuropathy. Diabetologia 1984;27:264A.

20 Faris I, Agerskov K, Henrikson O, Lassan NA, Parving H-H. Decreased distensibility of passive vascular bed in Diabetes Mellitus: An indicator of microangiopathy? Diabetologi 1982;23:411-4.

(Accepted 11 March 1986)

\section{YEARS AGO}

At a recent meeting of the Académie de Médecine, $M$. Polaillon showed fork that he had removed from the stomach of a professional swallower of forks and sabres, who swallowed the fork by mistake. The presence of the fork having been ascertained, by using $M$. Trouvè's oesophageal sound, the necessary operation was performed according to $M$. Labbé's method. The stomach was opened at the level of the ninth rib, and the fork, measurin twenty-one centimètres ( $81 / 4$ inches), was extracted. (British Medical fouma 1886;ii:466.) 